Please do not remove this page

RMIT

UNIVERSITY

\title{
Nanocomposite carbon-PDMS membranes for gas separation
}

Nour, Majid Kamal; Berean, Kyle; Griffin, Matthew; Matthews, Glenn; Bhaskaran, Madhu; Sriram, Sharath; Kalantar Zadeh, Kourosh

https://researchrepository.rmit.edu.au/esploro/outputs/9921858213201341/filesAndLinks?institution=61RMIT_INST\&index=null

Nour, M. K., Berean, K., Griffin, M., Matthews, G., Bhaskaran, M., Sriram, S., \& Kalantar Zadeh, K. (2012).

Nanocomposite carbon-PDMS membranes for gas separation. Sensors and Actuators B: Chemical, 161(1), 982-988. https://doi.org/10.1016/j.snb.2011.11.079

Document Version: Accepted Manuscript

Published Version: https://doi.org/10.1016/j.snb.2011.11.079

Repository homepage: https://researchrepository.rmit.edu.au

(C) 2011 Elsevier B.V.

Downloaded On 2023/04/26 22:22:46 +1000

Please do not remove this page 
Thank you for downloading this document from the RMIT Research Repository.

The RMIT Research Repository is an open access database showcasing the research outputs of RMIT University researchers.

RMIT Research Repository: http://researchbank.rmit.edu.au/

\section{Citation:}

Nour, M, Berean, K, Griffin, M, Matthews, G, Bhaskaran, M, Sriram, S and Kalantar Zadeh, K 2012, 'Nanocomposite carbon-PDMS membranes for gas separation', Sensors and Actuators B: Chemical, vol. 161, no. 1, pp. 982-988.

See this record in the RMIT Research Repository at:

http://researchbank.rmit.edu.au/view/rmit:14331

Version: Accepted Manuscript

Copyright Statement: (C) 2011 Elsevier B.V.

Link to Published Version:

http://dx.doi.org/10.1016/j.snb.2011.11.079 


\title{
Nanocomposite Carbon-PDMS Membranes
}

\section{for Gas Separation}

\author{
Majid Nour, Kyle Berean, Matthew J. Griffin, Glenn I. Matthews, \\ Madhu Bhaskaran, Sharath Sriram, and Kourosh Kalantar-zadeh* \\ School of Electrical and Computer Engineering, RMIT University, Melbourne, Australia \\ * Corresponding author. E-mail: kourosh.kalantar@rmit.edu.au
}

\begin{abstract}
Polydimethylsiloxane (PDMS) composites containing variable weight amounts of carbon black (CB) have been synthesized as membranes to evaluate the effect of $\mathrm{CB}$ concentration on gas selectivity and separation. The membranes were used in conjunction with a commercial semiconducting methane $\left(\mathrm{CH}_{4}\right)$ gas sensor that had a strong cross-talk with hydrogen $\left(\mathrm{H}_{2}\right)$ gas. The selectivity of the CB-PDMS composite membranes for gas separation was tested using $\mathrm{CH}_{4}$ and $\mathrm{H}_{2}$. It was found that at 6 wt $\%$ of $\mathrm{CB}$ in PDMS, the permeability of $\mathrm{CH}_{4}$ was significantly and selectively attenuated through the composite membrane. This work demonstrates that $\mathrm{CB}$ is an effective additive for tuning $\mathrm{H}_{2} / \mathrm{CH}_{4}$ gas selectivity of the composite membranes. The selectivity is attributed to a chemical transition occurring with increasing $\mathrm{CB}$ doping, which was observed by vibrational spectroscopy measurements.
\end{abstract}

Keywords: polydimethylsiloxane (PDMS); carbon black (CB); nanocomposite membrane; hydrogen $\left(\mathrm{H}_{2}\right)$; methane $\left(\mathrm{CH}_{4}\right)$; selectivity; separation ; FTIR; Raman. 


\section{Introduction}

Blocking an environmentally harmful gas or purifying a useful gas is required for many industrial, environmental, and biomedical applications [1,2]. Additionally, gas separation techniques are showing increasing demand for many sensing processes [3-5]. Many of the current gas sensor technologies suffer significantly from cross-talk and interferences of non-target gas species [6-9]. For example, semiconducting $\mathrm{H}_{2}$ gas sensors commonly show cross-talk with other reducing gases such as $\mathrm{CO}$ and $\mathrm{CH}_{4}[6,7]$. Gas separation is also essential to selective sensing technologies, as the presence of interfering gas species can be harmful, even corrosive, to the gas sensing elements. For instance, the presence of gas species such as $\mathrm{SO}_{2}$ and gaseous $\mathrm{HCl}$, which produce strong acidic environments, can reduce the lifetime of optical $\mathrm{CO}_{2}$ gas sensors [10].

Amongst conventional methods for gas separation, membrane technology has been widely embraced and commercially adopted, due to its efficiency and cost $[2,11-13]$. These gas selective membranes are also becoming increasingly incorporated in semiconducting and electrochemical sensors. Such selective membranes are used: (a) within the sensor package, reducing the effect of non-desired gases on the sensitive element of the gas sensors, or (b) as coating layers formed on the surface of the gas sensitive layers in semiconducting sensors [5] or on the surface of electrodes in electrochemical sensors $[8,14]$.

Polymer science has increasingly provided new grounds for creating novel membrane technologies [13]. One of the polymers commonly used for developing gas selective membranes is polydimethylsiloxane (PDMS) [15-17]. PDMS is widely utilized in microdevices and systems, due to its versatile and favorable properties, which include nontoxicity, biocompatibility, flexibility, low cost, and ease of fabrication [18]. Also advantageously amongst polymers manufactured industrially, PDMS has the highest gas 
permeability $[17,19,20]$. However, polymers with high permeability are generally less selective to gas species [13], and similarly PDMS is also a non-selective polymer, allowing most of the gases to effectively permeate through the material.

In order to enhance polymers selectivity, researchers have been considering the use of fillers for creating unique composites [21]. Adding these fillers can offer composites the capability of tuning properties such as conductivity, strength and, for our purpose, gas selectivity. Selectivity within polymers can be achieved using many types of fillers including metal oxides [22], and metals [23] as well as a host of other inorganic and organic fillers [24].

Carbon-based fillers such as carbon nanotubes (CNTs), carbon black (CB) and graphene, have been added to PDMS and other polymers to evaluate the effect on their properties [25]. Several investigations have been conducted on the incorporation of CNTs into PDMS for gas separation applications [26,27]. For instance, Kim et al. [26] have demonstrated that CNTs, if used in membranes, have the ability to separate gases. Their study has shown that CNT-based membranes have altered permeability to methane $\left(\mathrm{CH}_{4}\right)$. Most commonly, the CB particles have been used as fillers to prolong the lifespan of PDMS and to create polymers with tunable electrical and thermal conductivities [28]. In a commercial sense, CB particles are also regularly used in PDMS-based rubber tires in the automobile industry [29]. It has been shown that the infiltration of $C B$ into the polymer matrix enhances the stability of PDMS [30]. Additionally, it has also been demonstrated that the incorporation of carbon-based fillers within PDMS increases selectivity of the resultant membranes [28].

The intent of this study is to verify the hypothesis of increased separation of methane $\left(\mathrm{CH}_{4}\right)$ and hydrogen $\left(\mathrm{H}_{2}\right)$ utilizing CB-PDMS nanocomposites. The membranes are used in conjunction with a semiconducting commercial gas sensor that shows strong responses to both $\mathrm{H}_{2}$ and $\mathrm{CH}_{4}$. The hypothesis is tested by producing and testing composite 
membranes consisting of CB dispersed within PDMS. Our assumption is based on the well-known fact that carbon has a high affinity to hydrogen atoms [31]. As a result, introducing CB into PDMS should alter the selectivity of the membrane against $\mathrm{H}_{2}$ and $\mathrm{CH}_{4}$ at different concentrations of CB in the composite. In this work, the gas separation properties of the nanocomposite membranes were evaluated, and correlated to their chemical structure, using vibrational spectroscopy.

\section{Experimental}

\subsection{Membrane preparation}

Four different CB-PDMS nanocomposite membranes were prepared with CB weight percentages ranging from $2 \mathrm{wt} \%$ to $15 \mathrm{wt} \%$. First, the PDMS (Sylgard 184, Dow Corning) was prepared using 10:1 mixture of the base polymer and the curing agent. Next, CB powder (Vulcan XC72R, Cabot Inc.) was added to the PDMS matrix at the desired percentage by weight $(2 \%, 6 \%, 10 \%$, and $15 \%)$. The mixtures were then vigorously mixed until homogeneous pastes were obtained. After that, these pastes were placed in a vacuum oven at $60{ }^{\circ} \mathrm{C}$ for $\sim 10$ minutes for degassing. Finally, $7 \mathrm{~g}$ of the pastes were casted and levelled on glass plates of $100 \mathrm{~mm} \times 15 \mathrm{~mm}$ dimensions and cured at room temperature for over 2 days. This resulted in membranes with similar thicknesses of $0.08 \pm 0.02 \mathrm{~mm}$. 


\subsection{Characterization of CB-PDMS membranes}

The pure, reference PDMS and the nanocomposite CB-PDMS membranes were characterized by electron microscopy and vibrational spectroscopy techniques. The membrane cross-section was studied using FEI Nova NanoSEM scanning electron microscope. The Fourier transform infrared (FTIR) spectra of PDMS and CB-PDMS membranes were recorded using a Thermo Nicolet 6700 spectrophotometer at a resolution of $4 \mathrm{~cm}^{-1}$. A Renishaw InVia Raman spectrometer was used for performing micro-Raman characterization of the samples, which were analyzed at $633 \mathrm{~nm}$ wavelength with a laser power of $1.7 \mathrm{~mW}$ and with $20 \mathrm{~s}$ exposures over 3 accumulations.

\subsection{Gas sensing setup}

To measure the permeability and selectivity of these membranes to $\mathrm{CH}_{4}$ and $\mathrm{H}_{2}$, a gas chamber setup was custom designed as shown in Figure 1. The setup is made of a main gas chamber with the dimensions of $17 \mathrm{~cm} \times 12 \mathrm{~cm} \times 5 \mathrm{~cm}$. The gas chamber has an inlet and outlet that allow the target gases to enter and leave. The chamber also has a $0.5 \mathrm{~cm}$ radius recess, where the membrane under investigation is placed. Outside the chamber, a commercial gas sensor is fixed against this membrane (see inset of Figure 1). The sensor and membrane is sealed in a way that only the diffused gas from the chamber and through the membrane can affect the sensor. A commercial and accurately calibrated $\mathrm{CH}_{4}$ semiconducting gas sensor (TGS 2611, Figaro, Inc., USA) was used in these experiments in order to continuously measure gas concentration that passed through the membrane to interact with this sensor. This sensor was chosen as, in addition to $\mathrm{CH}_{4}$, it also shows a strong response to $\mathrm{H}_{2}$. This cross-response is desirable because the sensor can be practically used for assessing the selectivity of the different membranes to $\mathrm{CH}_{4}$ and $\mathrm{H}_{2}$. According to the data sheet for TGS $2611 \mathrm{CH}_{4}$ 
sensor, response of this device to $\mathrm{CH}_{4}$ is approximately 1.5 times larger than its response to $\mathrm{H}_{2}$ for the same concentration of the gases (this ratio is only accurate in the range of $0.5 \%$ to $1.0 \%$ of these gases in ambient air).

A mass flow controller (MKS Instruments, Inc., USA) is used to feed the chamber with gas. The sensor measurements were acquired using a custom-made data acquisition system and analyzed using a MATLAB software-based program.

\section{Results and Discussion}

The nanocomposite CB-PDMS membranes were characterized using electron microscopy and vibrational spectroscopy techniques, to determine the characteristics of the CB-PDMS bonds at different CB concentrations.

\subsection{Membrane Characterization by Microscopy and Vibrational Spectroscopy}

\subsubsection{Cross-sectional electron microscopy}

Scanning electron microscopy (SEM) was used in order to examine the morphology of the membranes as well as the distribution of the CB nanoparticles into the polymer. For CBPDMS nanocomposites lower than $10 \mathrm{wt} \%$, samples were coated with gold to prevent charging, as they had a very low electrical conductivity [31].

Figure 2 shows the SEM micrographs of the prepared CB-PDMS composites. It was observed that particle dispersion was reasonably homogenous for all samples. The size and shape of the particles appeared irregular ranging in the order of 70 to $110 \mathrm{~nm}$. Visually it was seen that as the concentration of CB increased in the polymer, the 
dominant PDMS structure with $\mathrm{CB}$ particles changed to a composite structure. No exceptional morphological behavior was observed after the addition of CB particles at different concentrations.

\subsubsection{FTIR studies}

Figure 3 shows the FTIR spectra of pure PDMS and for different CB-PDMS composites. In the FTIR spectrum of pristine PDMS [32], $-\mathrm{CH}_{3}$ deformation vibration signatures, appear between $1400-1420 \mathrm{~cm}^{-1}$ and between $1240-1280 \mathrm{~cm}^{-1}$. The latter peak can be observed in Figure 3 at $1240 \mathrm{~cm}^{-1}$ and this appear to have a minor back shift as the percentage of CB increases in PDMS. A broad, multi-component peak ranging from 930 to $1200 \mathrm{~cm}^{-1}$, corresponding to symmetrical Si-O-Si stretching is also present. The peak at $918 \mathrm{~cm}^{-1}$ decreases and shifts to significantly lower wave numbers as the concentration of CB increase in PDMS. At 6 wt\% CB in PDMS, the ratio between the two transmissions at 918 $\mathrm{cm}^{-1}$ and $944 \mathrm{~cm}^{-1}$ changes (peaks with marked region in Figure 3). Similar to previous reports [32-34], Si-C bands and rocking peaks for $\mathrm{Si}\left(\mathrm{CH}_{3}\right)_{2}$ are observed in 825-865 and $785-815 \mathrm{~cm}^{-1}$ regions, respectively.

\subsubsection{Raman spectroscopy studies}

The Raman spectrum of our PDMS membrane is presented in Figure 4(a), with peaks that agree with typical PDMS spectra presented in previous works [35]. It has a Si-O-Si symmetric stretching peak at $488 \mathrm{~cm}^{-1}$. The $\mathrm{Si}-\mathrm{CH}_{3}$ symmetric rocking appears around $607 \mathrm{~cm}^{-1}$. At $708 \mathrm{~cm}^{-1}$ and $787 \mathrm{~cm}^{-1}$, Si-C symmetric stretching and $\mathrm{CH}_{3}$ asymmetric rocking appear, respectively. $\mathrm{CH}_{3}$ symmetric rocking, symmetric bending, asymmetric bending, symmetric stretching, and asymmetric stretching show around 862, 1262, 1412, 2907, and $2965 \mathrm{~cm}^{-1}$, respectively [35]. 
After incorporating CB into PDMS, the Si-O-Si symmetric stretching band at $488 \mathrm{~cm}^{-1}$ of the pure PDMS appears to fadeout as the concentration of CB increases [Figure 4(b)]. It is also observed that at $6 \mathrm{wt} \%$ the $607 \mathrm{~cm}^{-1}$ the $\mathrm{Si}-\mathrm{CH}_{3}$ symmetric rocking is the weakest of all mixtures.

In contrast, pure CB powder has two first-order peaks around 1350 and $1580 \mathrm{~cm}^{-1}$ which correspond to disordered and crystalline (graphitic) carbon, respectively [36]. These bands are relatively equal in the CB-PDMS composites. It can be seen from Figure $4(b, c)$ that as the concentration of $\mathrm{CB}$ increases, the intensity of these peaks increases. The peaks around $620 \mathrm{~cm}^{-1}$ are attributed to Si-C stretching band.

\subsection{Gas permeability and selectivity}

The permeability and selectivity of the membranes were tested at different concentrations of $\mathrm{CH}_{4}$ and $\mathrm{H}_{2}$ in ambient air, using the mass flow controller setup that was presented in Section 2.3. The measurements were conducted while the membranes were kept at room temperature and the Figaro sensor was biased as recommended (5 V DC applied to its heater) by the manufacturer and, during the gas exposure, the resistance across it was measured every $10 \mathrm{~s}$. In order to assess the gas permeability and cross talk for the membranes, the mass flow controller generated gas streams of different concentrations of $\mathrm{CH}_{4}, \mathrm{H}_{2}$, and their mixtures in ambient air were pumped into the chamber. First, $0.5 \%$ and $1.0 \% \mathrm{H}_{2}$ (in ambient air) were pumped, followed by ambient air after each cycle to allow for the sensor recovery. Subsequently, $0.5 \%$ and $1.0 \% \mathrm{CH}_{4}$ (also in ambient air) were pumped into the chamber, similarly with ambient air between the two cycles for recovery. At the end, a mixture of $0.5 \% \mathrm{H}_{2}$ and $0.5 \% \mathrm{CH}_{4}$ were pumped to observe the effect of a mixed gas environment. 
The exposure time for which different gas concentrations were pumped into the chamber was 15 min for $\mathrm{CH}_{4}$ and 10 minutes for $\mathrm{H}_{2}$ (due to its relatively faster gas diffusion through the membranes), while the ambient air for recovery was pumped for 20 and $30 \mathrm{~min}$ in between and after exposures, respectively. It was observed that the exposure time of 10 min was also sufficient for the mixture of $\mathrm{CH}_{4}$ and $\mathrm{H}_{2}$.

As these gases were pumped into the chamber, the commercial $\mathrm{CH}_{4}$ sensor behind the different membranes was used for measuring the concentrations of the analyte gases that passed through the membranes (Figure 1). Employing the commercial sensor in conjunction with the pure PDMS and nano-composite CB-PDMS membranes, when subject to different gas species and concentrations, the relative permeability ratios of different membranes for various gas species were determined. The dynamic response of sensing system at different concentrations of gases is shown in Figure 5, where the variation in resistance of the commercial sensor $R \mathrm{~s}$ as a function of gas exposure over time is presented. All measurements were taken at room temperature.

As can be seen in Figure 5, for 2, 6, and 15 wt\% CB-PDMS composites, the response magnitudes and their trends were fairly similar upon exposure to both $0.5 \%$ and $1.0 \% \mathrm{H}_{2}$ and fell within the maximum and minimum $50 \%$ range of the values. Additionally, at these mixtures the baselines were quite stable. However, at $10 \mathrm{wt} \% \mathrm{CB}$ composite and to a lesser degree for the pure PDMS, the baselines gradually shifted upwards and were not as stable. This effect resulted in a change in the value of $R \mathrm{~s}$ when the $\mathrm{H}_{2}$ concentration increased, which disordered the $\mathrm{H}_{2}$ response trend. The baseline shift effect was dramatically reduced after repeated measurements, when both the membranes and sensor reached a high degree of stability.

To assess the membranes' gas selectivity and their relative permeability for each gas species, we obtained the normalized permeability for each case (Figure 6). First, 
responses of the sensor/membrane systems to $\mathrm{H}_{2}$ gas was multiplied by 1.5 due to the fact that the Figaro gas sensor response to a $\mathrm{H}_{2}$ gas concentration is 1.5 less than that of the same concentration of $\mathrm{CH}_{4}$. Second, the response of the system incorporating $2 \mathrm{wt} \%$ CB in PDMS membrane to $\mathrm{H}_{2}$ was used as the base for the normalization, as it provided the largest response. It should be considered that before the normalization the responses of the membranes to $\mathrm{H}_{2}$ gas was multiplied by 1.5 due to the fact that the Figaro gas sensor response to a $\mathrm{H}_{2}$ gas concentration is 1.5 less than that of the same concentration of $\mathrm{CH}_{4}$. As can be seen in Figure 6, the presence of CB in PDMS has slightly enhanced the permeability to $\mathrm{H}_{2}$ through the composite membranes. This is in agreement with our earlier hypothesis that carbon-loading enhances $\mathrm{H}_{2}$ diffusion, as carbon has an affinity to $\mathrm{H}_{2}$. Conversely, embedding $\mathrm{CB}$ in PDMS has significantly attenuated the permeability of the membranes to $\mathrm{CH}_{4}$. The optimum condition for almost completely blocking $\mathrm{CH}_{4}$ diffusion, while allowing the passage of $\mathrm{H}_{2}$, was obtained at $6 \mathrm{wt} \% \mathrm{CB}$ loading.

A described in Section 3.1.2 and revealed from our FTIR investigations (Figure 3), at 6 wt\% CB in PDMS, the ratio between the two transmissions at $918 \mathrm{~cm}^{-1}$ and $944 \mathrm{~cm}^{-1}$ changes. This appears to relate to the membrane permeability to $\mathrm{CH}_{4}$ as we have more non-polymerized bonds between $\mathrm{Si}$ and $\mathrm{O}$, which facilitate the interaction of $\mathrm{CH}_{4}$ with the membrane. Moreover, $\mathrm{Si}-\mathrm{C}$ bands around $825-865 \mathrm{~cm}^{-1}$. and rocking in $\mathrm{Si}\left(\mathrm{CH}_{3}\right)_{2}$ in $785-$ $815 \mathrm{~cm}^{-1}$ were also observed. These changes suggest that the $6 \mathrm{wt} \%$ CB PDMS composite is a transition point, where the chemical bond structure starts to change. This transitory structure appears to be responsible for $\mathrm{CH}_{4}$ blockage. As the concentration of CB increases, the CB-PDMS bonds start to become increasingly cross-linked, which again enables $\mathrm{CH}_{4}$ permeation [37].

From the Raman spectra (Figure 4), it was seen that at $6 \mathrm{wt} \%$ the $\mathrm{Si}-\mathrm{CH}_{3}$ symmetric rocking is the weakest, in comparison to the other CB concentrations. As a result, it is 
likely that at this concentration, Si establishes the optimum number of bonds with the carbon from the CB matrix.

The results obtained from the vibrational spectroscopy analyses (FTIR and Raman) both suggest and support that $\mathrm{Si}-\mathrm{O}$ bond plays a major role in the membrane permeability characteristics. As the concentration of CB reaches $6 \mathrm{wt} \%$, a chemical transition exists, where the number of non-polymerized Si-O bonds increase, which appears to relate to the prevention of $\mathrm{CH}_{4}$ molecules from passing through the composite membrane. Moreover, as the concentration of $\mathrm{CB}$ reaches $15 \mathrm{wt} \%$, the microscopy and vibrational spectra indicate that PDMS is significantly modified resulting in a new composite material.

\section{Conclusion}

In this work, a number of weight concentrations of CB in CB-PDMS nanocomposite membranes were fabricated. The effect of the CB concentration on membrane selectivity to $\mathrm{CH}_{4}$ and $\mathrm{H}_{2}$ was studied. It was found that in general the presence of $\mathrm{CB}$ in PDMS enhances the selectivity of the membranes toward $\mathrm{H}_{2}$ over $\mathrm{CH}_{4}$. A specific, optimal weight ratio of CB (6 wt\%) in PDMS was found to produce nanocomposites with increased selectivity to permeation of $\mathrm{H}_{2}$ by efficient blocking of $\mathrm{CH}_{4}$. Such selective permeability membranes can enable in situ selective $\mathrm{H}_{2}$ gas measurement, using low cost semiconducting gas sensors, as most semiconducting gas sensors are also sensitive to $\mathrm{CH}_{4}$ and other gas species. We plan to extend this study in the future by testing these membranes in both aqueous environments. 


\section{Acknowledgements}

MN acknowledges the Saudi Arabian Ministry of Higher Education for Financial support. MB and SS acknowledge the Australian Post-Doctoral Fellowships from the Australian Research Council through Discovery Projects DP1092717 and DP110100262, respectively. SS and KKZ acknowledge the Australian Research Council for equipment funding through the Linkage, Infrastructure, Equipment, and Facilities Grant LE100100215.

\section{References}

[1] K. Ghosal, B.D. Freeman, Gas separation using polymer membranes: An overview, Polym. Advan. Technol. 5 (1994) 673-697.

[2] M. Hong, R.D. Noble, J.L. Falconer, Highly selective $\mathrm{H}_{2}$ separation zeolite membranes for coal gasification membrane reactor applications, Technical Report, University of Colorado (2004).

[3] B. Adhikari, S. Majumdar, Polymers in sensor applications, Prog.Polym. Sci. 29 (2004) 699-766.

[4] V.K. Gupta, N. Arunima, B. Singhal, S. Agarwal, Recent advances on potentiometric membrane sensors for pharmaceutical analysis, Combinator.Chem. High Throughput Screen. 14 (2011) 284-302.

[5] M.P. Rina, R. Mallada, M. Arruebo, M. Urbiztondo, N. Navascués, O. De La Iglesia, J. Santamaria, Zeolite films and membranes. Emerging applications. Micropor. Mesopor. Mater. 144 (2011) 19-27.

[6] C. Imawan, H. Steffes, F. Solzbacher, E. Obermeier, A new preparation method for sputtered MoO3 multilayers for the application in gas sensors, Sens. Act. B Chem. 78 (2001) 119-125. 
[7] A.Z. Sadek, S. Choopun, W. Wlodarski, S.J. Ippolito, K. Kalantar-zadeh, Characterization of $\mathrm{ZnO}$ nanobelt-based gas sensor for $\mathrm{H}_{2}, \mathrm{NO}_{2}$, and hydrocarbon sensing, IEEE Sens. J. 7 (2007) 919-924.

[8] D.S. Silvester, Recent advances in the use of ionic liquids for electrochemical sensing, Analyst 136 (2011) 4871-4882.

[9] G. Erdogdu, E. Ekinci, A.E. Karagozler, Preparation and electrochemical behavior of dopamine - selective polymeric membrane, Polym. Bull. 44 (2000) 195-201.

[10] I.M. Pérez de Vargas-Sansalvador, M.A. Carvajal, O.M. Roldán-Muñoz, J. Banqueri, M.D. Fernández-Ramos, L.F. Capitán-Vallvey, Phosphorescent sensing of carbon dioxide based on secondary inner-filter quenching, Analytica Chimica Acta 655 (2009) 66-74.

[11] M.R. Anderson, B.R. Mattes, H. Reiss, R.B. Kaner, Gas separation membranes: A novel application for conducting polymers, Syn. Met. 41 (1991) 1151-1154.

[12] B.D. Freeman, Basis of permeability/selectivity tradeoff relations in polymeric gas separation membranes. Macromol. 32 (1999) 375-380.

[13] L.M. Robeson, Polymer membranes for gas separation, Curr. Opin. Solid St. Mater. 4 (1999) 549-552.

[14] S.S. Park, C.E. Tatum, Y. Lee, Dual electrochemical microsensor for simultaneous measurements of nitric oxide and oxygen: Fabrication and characterization, Electrochem. Comm. 11 (2009) 2040-2043.

[15] X. Zhan, J. Li, J. Huang, C. Chen, Pervaporation Properties of PDMS Membranes Cured With Different Cross-Linking Reagents for Ethanol Concentration from Aqueous Solutions, Chinese J. Polym. Sci. 27 (2009) 533-542

[16] A. Ghadimi, M. Sadrzadeh, T. Mohammadi, Prediction of ternary gas permeation through synthesized PDMS membranes by using Principal Component Analysis (PCA) and fuzzy logic (FL), J. Membrane Sci.I. 360 (2010) 509-521. 
[17] T.C. Merkel, V. I. Bondar, K. Nagai, B.D. Freeman, I. Pinnau, Gas sorption, diffusion, and permeation in poly(dimethylsiloxane), J. Polym. Sci. Pol. Phys. 38 (2000) 415434.

[18] C. de Menezes Atayde, I. Doi, Highly stable hydrophilic surfaces of PDMS thin layer obtained by UV radiation and oxygen plasma treatments, Phys. Status. Solidi C. 7 (2010) 189-192.

[19] J.C. Lötters, W. Olthuis, P. H. Veltink, P. Bergveld, The mechanical properties of the rubber elastic polymer polydimethylsiloxane for sensor applications, J. Mictomech. Mictoeng. 7 (1997) 145.

[20] T. Nakagawa, T. Nishimura, A. Higuchi, Morphology and gas permeability in copolyimides containing polydimethylsiloxane block, J. Membrane Sci. 206 (2002) 149-163.

[21] B.M. Novak, Hybrid Nanocomposite Materials—between inorganic glasses and organic polymers, Adv. Mater. 5 (1993) 422-433.

[22] P. Pandey, R.S. Chauhan, Membranes for gas separation, Prog. Polym. Sci. 26 (2001) 853-893.

[23] Y. Vijay, The titanium-coated polymeric membranes for hydrogen recovery, Int. J. Hydrogen Energ. 27 (2002) 905-908.

[24] T. Chung, L.Y. Jiang, Y. Li, S. Kulprathipanja, Mixed matrix membranes (MMMs) comprising organic polymers with dispersed inorganic fillers for gas separation, Prog. Polym. Sci. 32 (2007) 483-507.

[25] Z.G, Huang, Z.P. Guoa, A. Calka, D. Wexler, H.K. Liu, Effects of carbon black, graphite and carbon nanotube additives on hydrogen storage properties of magnesium, J. Alloy. Compd. 427 (2007) 94-100.

[26] S. Kim, T.W. Pechar, E. Marand, Poly(imide siloxane) and carbon nanotube mixed matrix membranes for gas separation, Desalination, 129 (2006) 330-339. 
[27] J. Lou, S. Ilias, Development of Nanofiller-Modulated Polymeric Oxygen Enrichment Membranes for Reduction of Nitrogen Oxides in Coal Combustio, Department of Mechanical and Chemical Engineering North Carolina A\&T State University, (2009).

[28] I.F.J Vankelecom, J.D. Kinderen, B.M. Dewitte, J.B. Uytterhoeven Incorporation of Hydrophobic Porous Fillers in PDMS Membranes for Use in Pervaporation. J. Phys. Chem. B. 101 (1997) 5182-5185.

[29] J.C. Huang, Carbon black filled conducting polymers and polymer blends. Adv. Polym. Tech. 21 (2002) 299-313.

[30] A.I. Medalia, Effect of Carbon Black on Dynamic Properties of Rubber Vulcanizates, Rubber Chem. Technol. 51 (1978) 437-523.

[31] X.Z. Niu, S. Peng, L. Liu, W. Wen, P. Sheng, Characterizing and Patterning of PDMS-Based Conducting Composites, Adv. Mater. 19 (2007) 2682-2686.

[32] D. Maji, S.K. Lahiri, S. Das, Study of hydrophilicity and stability of chemically modified PDMS surface using piranha and KOH solution, Surf. Interface Anal. (2011)

[33] D. Bodas, C. Khan-Malek, Formation of more stable hydrophilic surfaces of PDMS by plasma and chemical treatments, Microelectronic Eng. 83 (2006) 1277-1279.

[34] R. Agarwal, P. Tandon, V.D. Gupta, Phonon dispersion in poly(dimethylsilane), J. Organomet. Chem. 691 (2006) 2902-2908.

[35] S.C. Bae, H. Lee, Z. Lin, S. Granick, Chemical Imaging in a Surface Forces Apparatus: Confocal Raman Spectroscopy of Confined Poly(dimethylsiloxane), Langmuir. 21 (2005) 5685-5688.

[36] T. Jawhari, A. Roid, J. Casado, Raman spectroscopic characterization of some commercially available carbon black materials, Carbon, 33 (1995) 1561-1565.

[37] J.M. O'Reilly, R.A. Mosher, Functional groups in carbon black by FTIR spectroscopy, Carbon. 21 (1983) 47-51. 


\section{Figure Captions}

Figure 1: Gas sensing setup depicting location of the gas selective membrane and the gas sensing module (not to scale).

Figure 2: Cross sectional SEM micrographs of CB-PDMS nanocomposite membranes of different concentrations, showing distribution and particle size, respectively for: $2 \mathrm{wt} \% \mathrm{CB}$ in (a) and (b); 6 wt\% CB in (c) and (d); and 15 wt\% CB in (e) and (f).

Figure 3: FTIR spectra for the pure PDMS and nanocomposite CB-PDMS membranes.

Figure 4: Micro-Raman spectra for: (a) pure PDMS; (b) three different CB concentrations in CB-PDMS nanocomposite membranes; and (c) marked wavenumber range in (b).

Figure 5: Dynamic response of the sensor-membrane system on exposure to different gas concentrations and mixtures.

Figure 6: Normalized relative permeability of CB-PDMS membranes to various concentrations of $\mathrm{CH}_{4}$ and $\mathrm{H}_{2}$ in ambient air. 


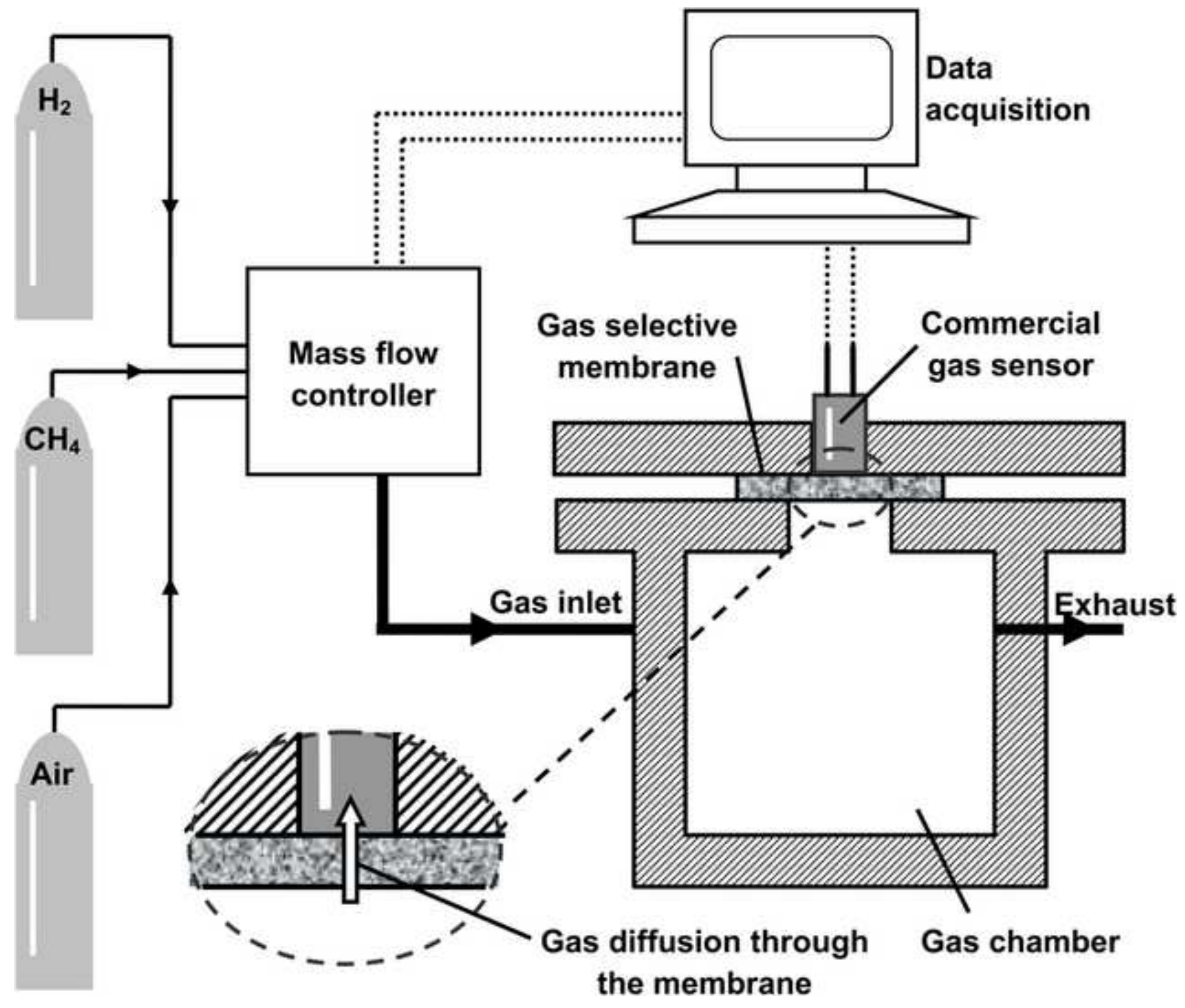


Click here to download high resolution image

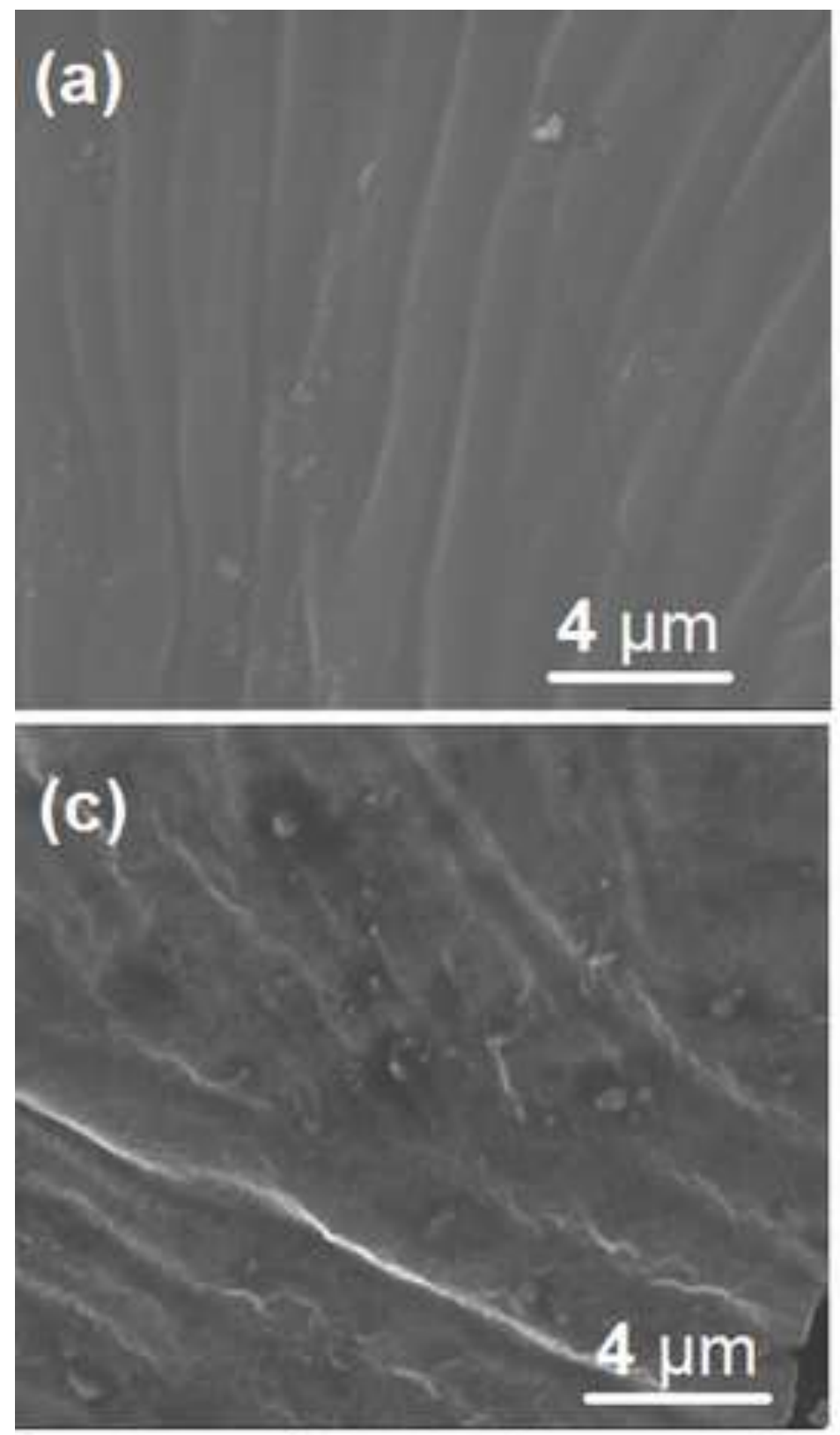

(b)

(d)

\section{$2 \mu \mathrm{m}$}
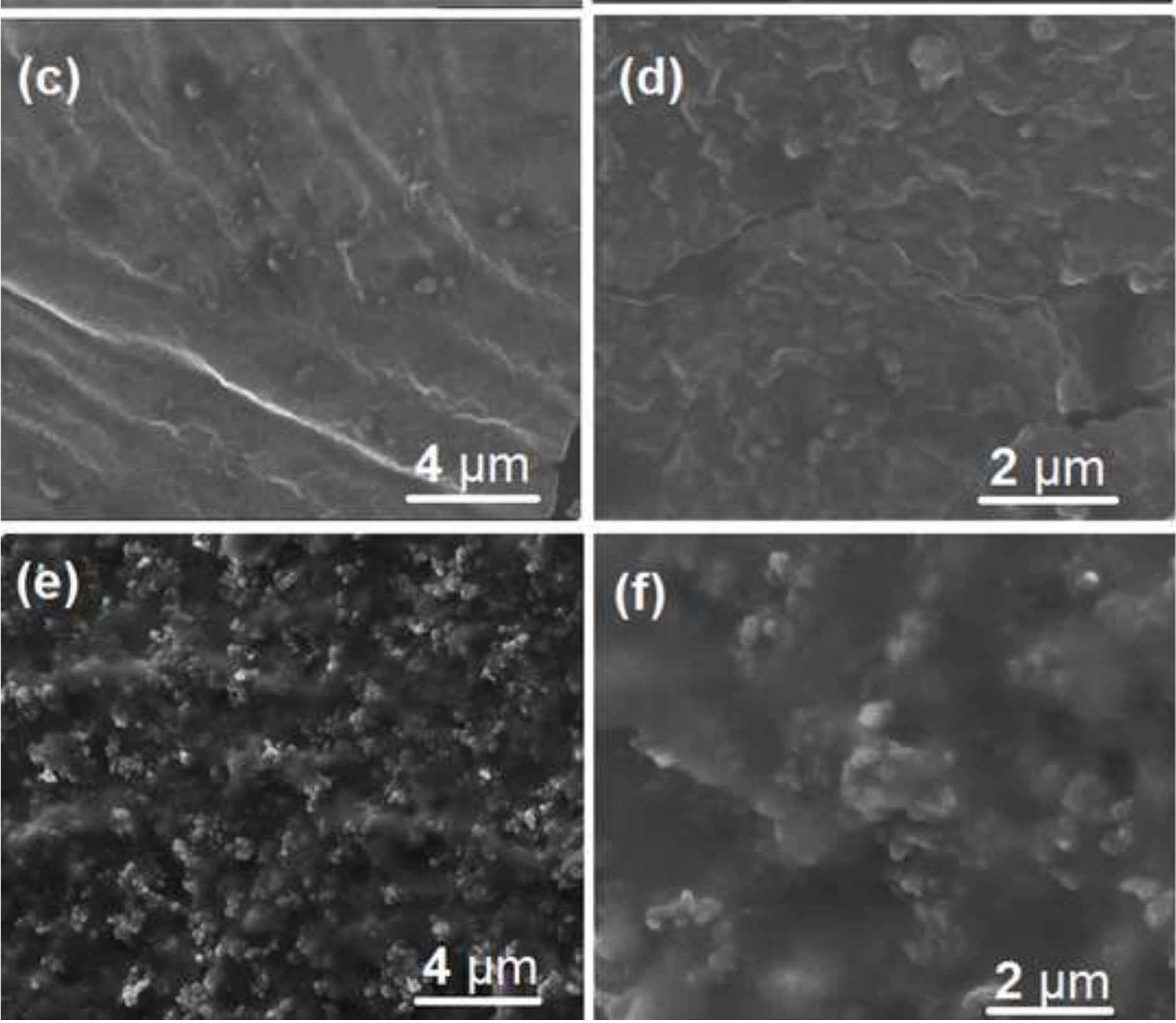

(f) 


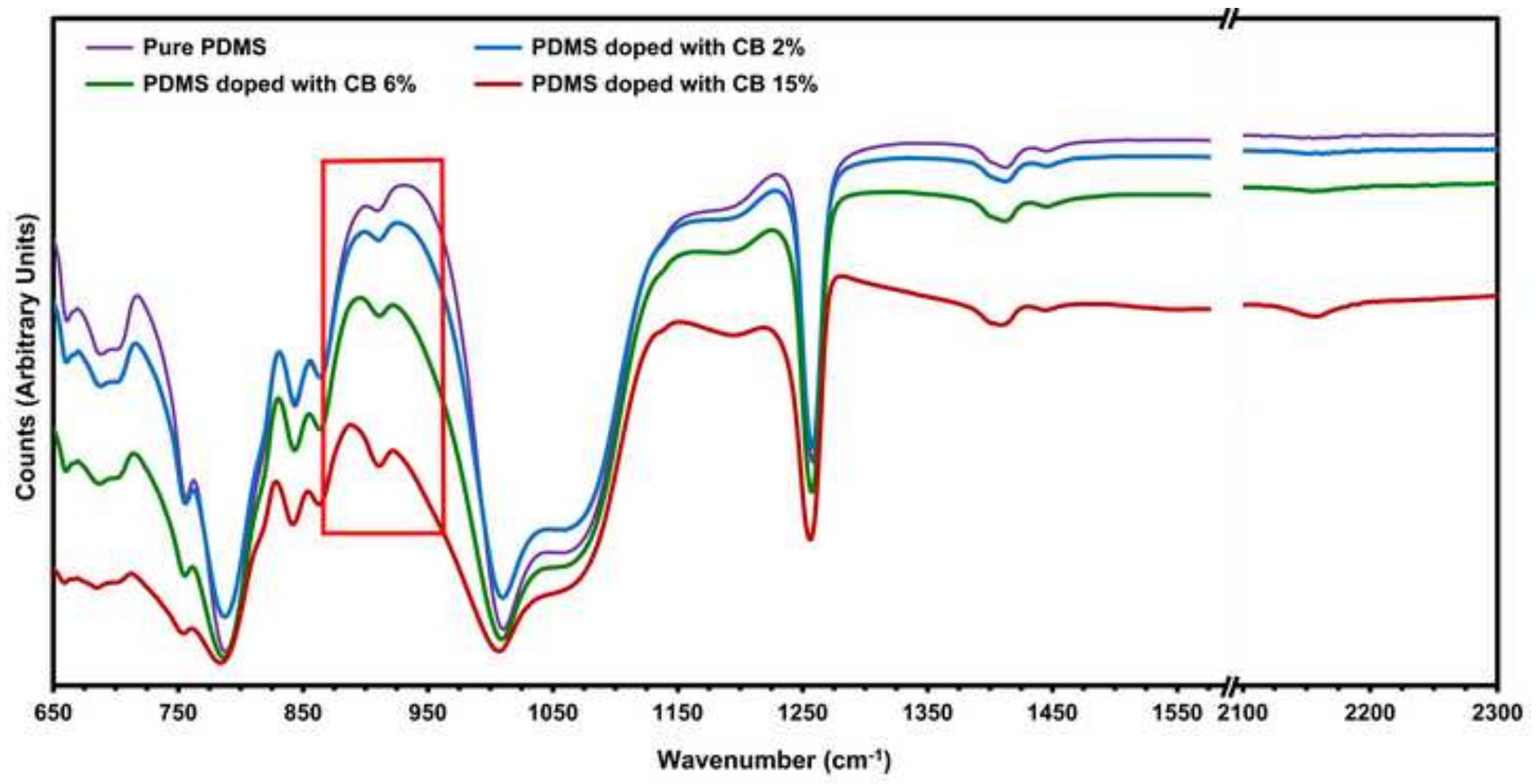




\section{Figure 4}

Click here to download high resolution image
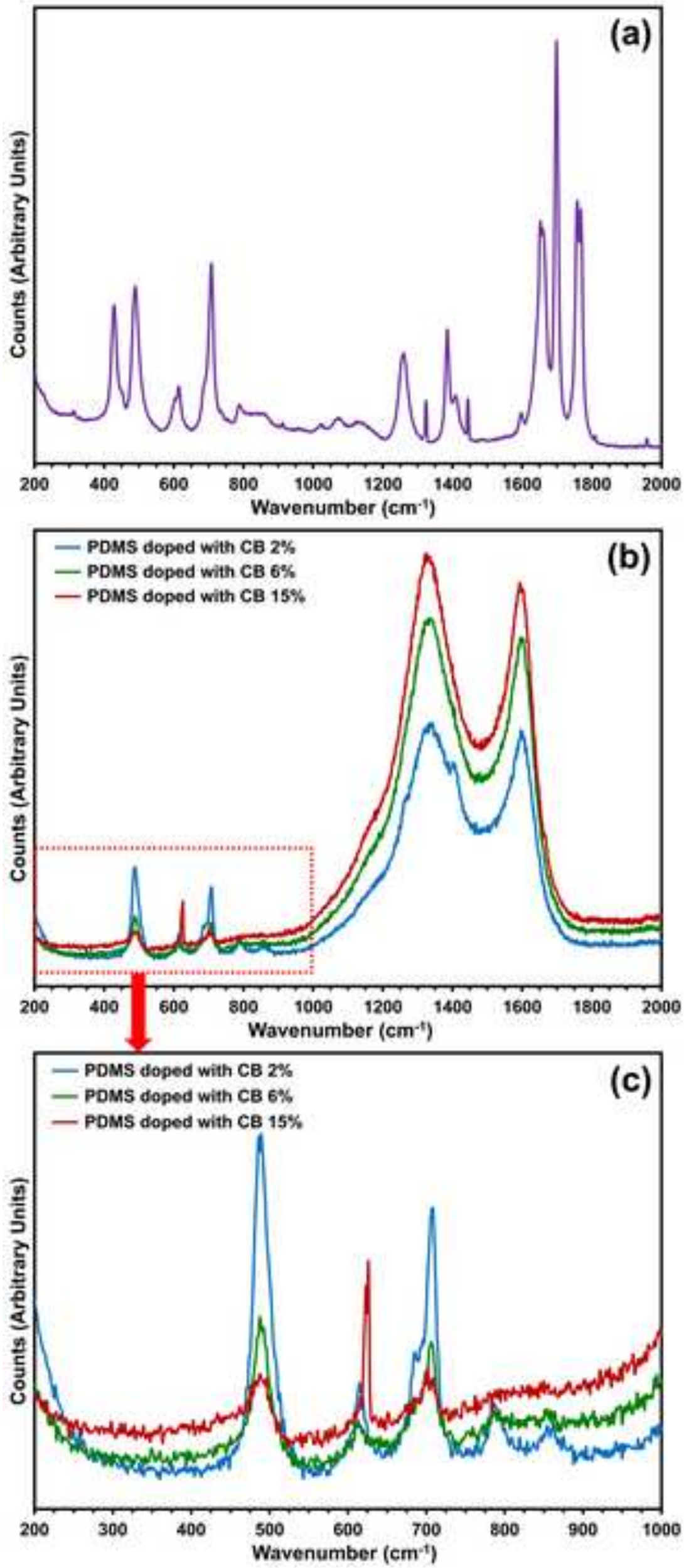


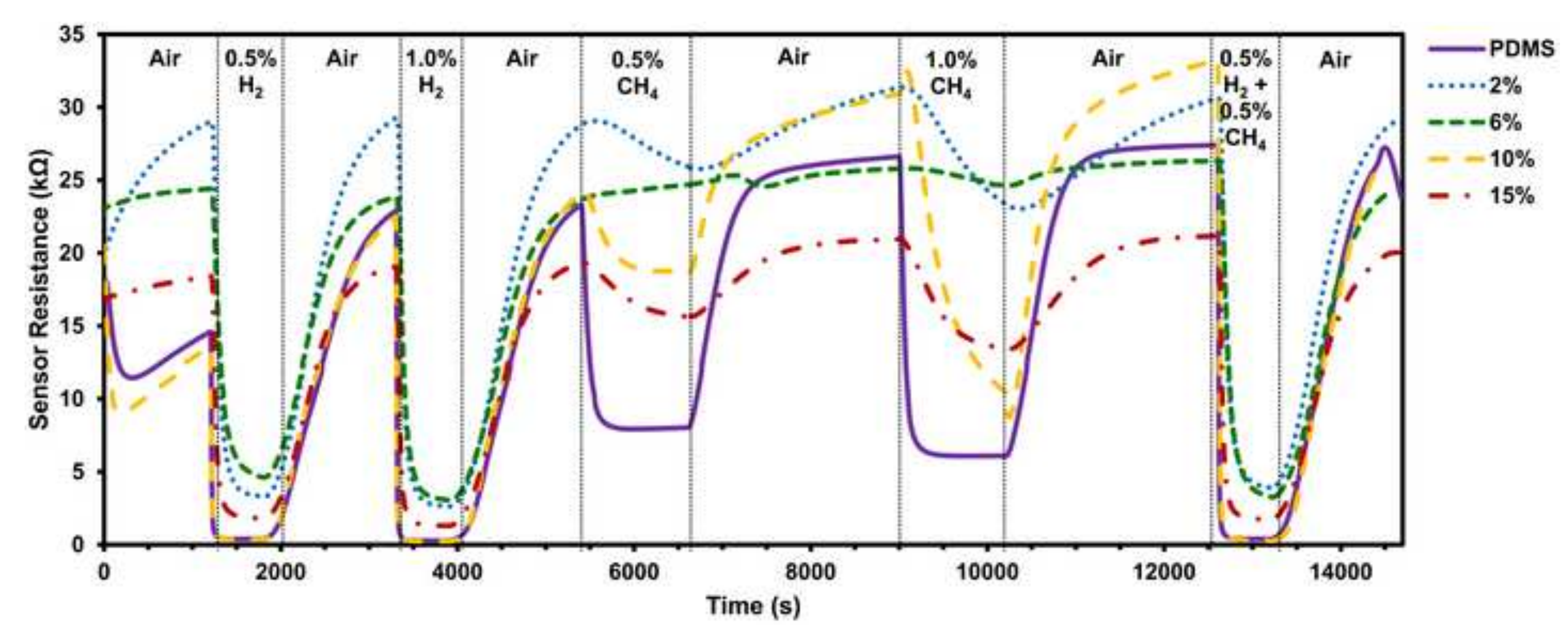




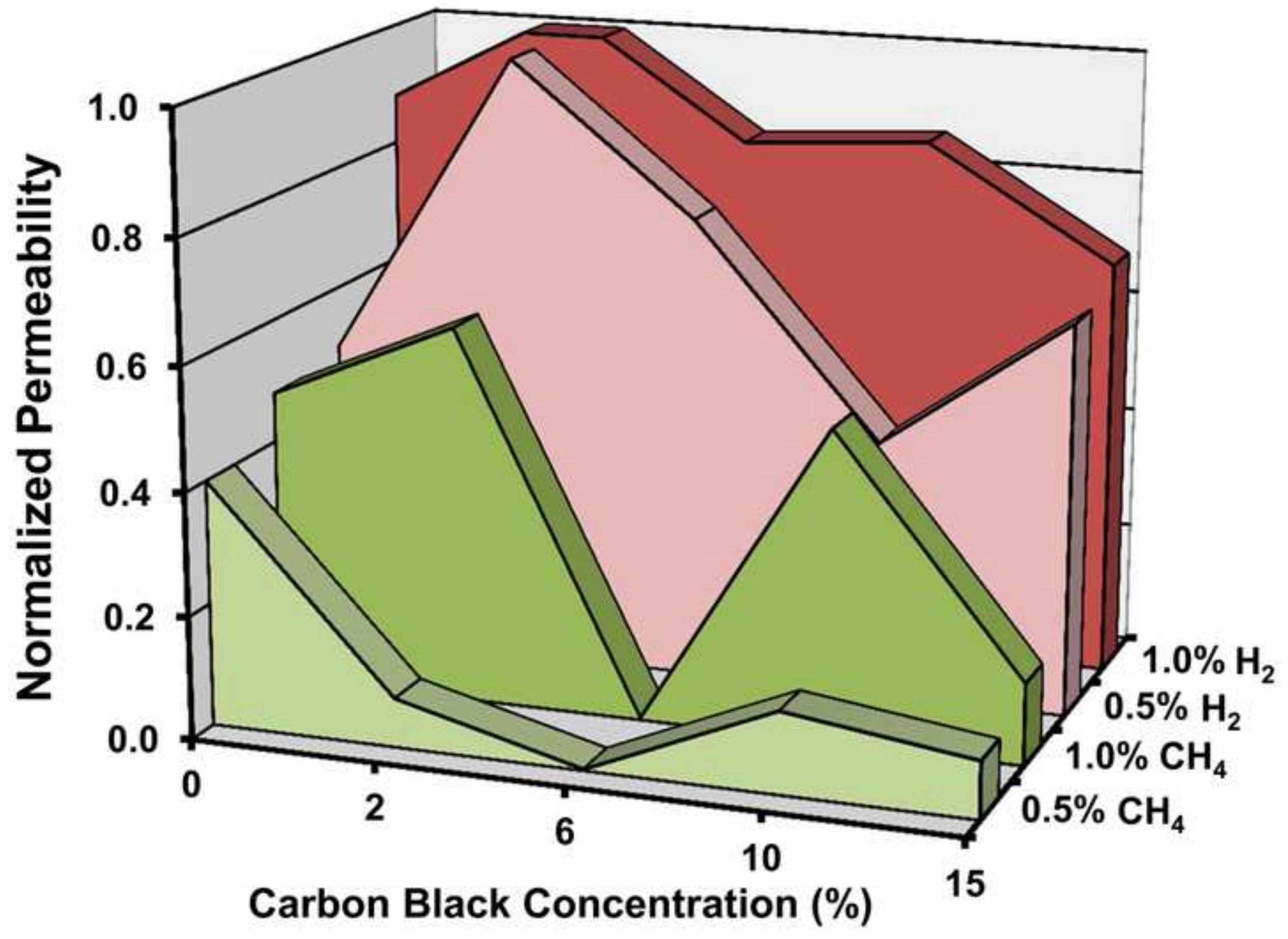

